\title{
Extremely Early Summer Monsoon Onset in the South China Sea in 2019 Following an EI Niño Event
}

\author{
Peng Hu, Wen Chen, And Shangfeng Chen \\ Center for Monsoon System Research, Institute of Atmospheric Physics, Chinese Academy of Sciences, and \\ College of Earth and Planetary Sciences, University of Chinese Academy of Sciences, Beijing, China \\ YUYUN LIU \\ Center for Monsoon System Research, Institute of Atmospheric Physics, Chinese Academy of Sciences, Beijing, China

\section{RUPING HUANG} \\ Guangzhou Institute of Tropical and Marine Meteorology, China Meteorological Administration, Guangzhou, China
}

(Manuscript received 26 September 2019, in final form 3 March 2020)

\begin{abstract}
The El Niño-Southern Oscillation (ENSO) is regarded as one of the most important factors for onset of the South China Sea summer monsoon (SCSSM). Previous studies generally indicated that an El Niño event tends to result in a late onset of the SCSSM monsoon. However, this relationship has not been true in recent years, particularly when an extremely early SCSSM onset (1 May 2019) occurred following the 2018/19 El Niño event in the preceding winter. The processes of the second earliest SCSSM onset in the past 41 years were investigated using NCEP-DOE reanalysis, OLR data, and ERSST. A negative sea surface temperature and associated anticyclonic anomalies were absent over the western North Pacific in the late spring of 2019 following an El Niño event in the preceding winter. Thus, the mean circulation in the late spring of 2019 does not prevent SCSSM onset, which is in sharp contrast to the composited spring of the El Niño decaying years. The convective active and westerly phases of a 30-60-day oscillation originating from the Indian Ocean provided a favorable background for the SCSSM onset in 2019. In addition, the monsoon onset vortex over the Bay of Bengal and the cold front associated with a midlatitude trough over East Asia also played important roles in triggering the early onset of the SCSSM in 2019. No tropical cyclone appeared over the western North Pacific during April and May, and the enhancement of quasi-biweekly oscillation mainly occurs after the SCSSM onset; thus, these two factors contribute little to the SCSSM onset in 2019.
\end{abstract}

\section{Introduction}

The onset of the summer monsoon is the most prominent subseasonal phenomena of the monsoon system, which is signified by dramatic changes of large-scale atmospheric circulation and the arrival of the wet season. While the seasonal reversals of surface wind and rainfall recur each year, the abnormal monsoon onset can lead to severe drought and flood events and thus affect local agriculture and planting. Moreover, atmospheric teleconnections accompanying monsoon onset could impact climate variations over remote regions. Therefore, investigating monsoon onset

Corresponding author: Dr. Shangfeng Chen, chenshangfeng@ mail.iap.ac.cn cannot only improve our understanding of monsoon dynamics, but also because it has significant socioeconomic impacts.

In general, the onset of the Asian summer monsoon first occurs over the Bay of Bengal (BOB) in late April, followed by the South China Sea (SCS) in mid-May, and finally over South Asia in early June (Wu and Zhang 1998; Wang and LinHo 2002; Li and Zhang 2009; Liu et al. 2015). The onset of the South China Sea summer monsoon (SCSSM) not only signifies the onset of the East Asian summer monsoon and western North Pacific (WNP) summer monsoon but also marks the beginning of the major rainy season (Lau and Yang 1997; Wu and Wang 2001; Wang and LinHo 2002; Wu 2002; Ding et al. 2004; Wang et al. 2004; Ding and Chan 2005; Ding 2007; Wang et al. 2009; Ding et al. 2015). Moreover, the 
variability of SCSSM onset is closely related to summertime climate anomalies. For example, a late SCSSM onset is accompanied by increased rainfall over the middle and lower reaches of the Yangtze River basin during May and this relationship is maintained by the circulation anomalies excited by the latent heating associated with monsoon onset (Jiang et al. 2018). In addition, the late SCSSM onset tends to be succeeded by an above-normal total rainfall amount during the entire summer over the lower reaches of the Yangtze River basin (Huang et al. 2006; He and Zhu 2015). The persistent WNP anticyclone from late-spring to summer is responsible for the above relationship, which is related to the thermal state of the tropical Indo-Pacific Ocean (Wang et al. 2000; Xie et al. 2009, 2016; Li et al. 2017). Kajikawa and Yasunari (2005) reported that a late SCSSM onset is usually followed by active quasi-biweekly oscillation in June-July, while an early monsoon onset tends to be followed by active 30-60-day oscillation. A recent study revealed an out-ofphase relationship between SCSSM onset and the frequency of landfalling tropical cyclones (TCs) in mainland China (Wang and Chen 2018).

Due to the importance of the SCSSM onset stated above, substantial efforts have been made to investigate the factors that modulate monsoon onset, especially after the South China Sea Monsoon Experiment (SCSMEX) launched in 1998 (e.g., Lau et al. 2000; Chen et al. 2001; Ding and Liu 2001; Ding et al. 2004). Due to the special location of the SCSSM (Wang and Wu 1997; Wang et al. 2009), its onset can be affected by disturbances originating from multiple directions, for example, the cross-equatorial flow (Lin et al. 2017; Hu et al. 2018b) and intertropical convergence zone (Zhou et al. 2005; Kajikawa and Wang 2012; Hu et al. 2018b) from the south, TC (Mao and Wu 2008; Kueh and Lin 2010; Kajikawa and Wang 2012; Chen 2015; Huangfu et al. 2017) and quasi-biweekly oscillation (Chen and Chen 1995; Zhou and Chan 2005; Wu 2010; Lee et al. 2013) from the east, the Madden-Julian oscillation (MJO) and/or 30-60-day oscillation (Chen and Chen 1995; Zhou and Chan 2005; Straub et al. 2006; Tong et al. 2009; Shao et al. 2015; Wang et al. 2018) and monsoon onset vortex (Krishnamurti et al. 1981; Krishnakumar et al. 1993; Lau et al. 1998, 2000; Ding and Liu 2001; Liu et al. 2002; Ding et al. 2004; Wu et al. 2005, 2012; Xing et al. 2016) from the west, and the cold front (Chang and Chen 1995; Ding and Liu 2001; Tong et al. 2009; Kueh and Lin 2010; Huangfu et al. 2018) and other extratropical factors (e.g., Luo et al. 2016; Liu and Zhu 2019) from the north. The MJO is regarded as a prominent background for SCSSM onset, and most of the SCSSM onsets occur when the active convection related to the
MJO is located around the western Pacific (Chen and Chen 1995; Tong et al. 2009; Lin et al. 2016; Hu et al. 2019). However, some SCSSM onsets occurred in the presence of local suppressed convection phases of the MJO. A recent study (Shao et al. 2015) suggests that the tendency of convection is as important as its absolute value, and a developing ISO (from inactive convection to active convection) plays a more important role in contributing to the onset of SCSSM.

It is well known that the sea surface temperature (SST) anomalies over the Indo-Pacific Ocean are among the most important external factors modulating the onset of SCSSM. Numerous studies have demonstrated that a preceding warm El Niño-Southern Oscillation (ENSO) (i.e., El Niño) event can delay monsoon onset (Ding and Liu 2001; Zhou and Chan 2007; Liu et al. 2016; Luo et al. 2016; He et al. 2017; Luo and Lin 2017; Zhu and Li 2017; Martin et al. 2019) by mainly modulating the tropical Walker circulation (Webster and Yang 1992; Xie et al. 1998; Liang et al. 2013; Luo et al. 2016) and exciting an anomalous anticyclone over the WNP (Wang et al. 2000; Yuan et al. 2008; Xie et al. 2009, 2016; Zhang et al. 2017; Li et al. 2017). Furthermore, ENSO is one of the most important predictors for the SCSSM onset in both empirical prediction (Zhu and $\mathrm{Li}$ 2017) and dynamic prediction (Martin et al. 2019). However, the in-phase ENSO-SCSSM onset relationship failed in 2018 when an extremely late onset occurred following a La Niña event, which could be related to the weaker Mongolian cyclone over the midlatitudes (Liu and Zhu 2019). This ENSO-SCSSM relationship again breaks down in 2019, when an extremely early onset occurred following an El Niño event, which is the focus of the present study. This study will examine the onset processes of SCSSM in this year and determine the possible causes responsible for the extremely early onset.

The rest of the manuscript is organized as follows: section 2 introduces the datasets and methods, section 3 presents a case study of extremely early SCSSM onset in 2019 following an El Niño event, and finally, the summary and discussion are presented in section 4 .

\section{Data and methods}

The major datasets employed in this analysis include the following: 1) daily National Centers for Environmental Prediction-Department of Energy (NCEP-DOE) reanalysis data (Kanamitsu et al. 2002) with a horizontal resolution of $2.5^{\circ} \times 2.5^{\circ}$; 2) daily outgoing longwave radiation (OLR) data (Schreck et al. 2018) with a horizontal resolution of $1^{\circ} \times 1^{\circ}$; and 3) monthly Extended Reconstructed Sea Surface Temperature, version 5 

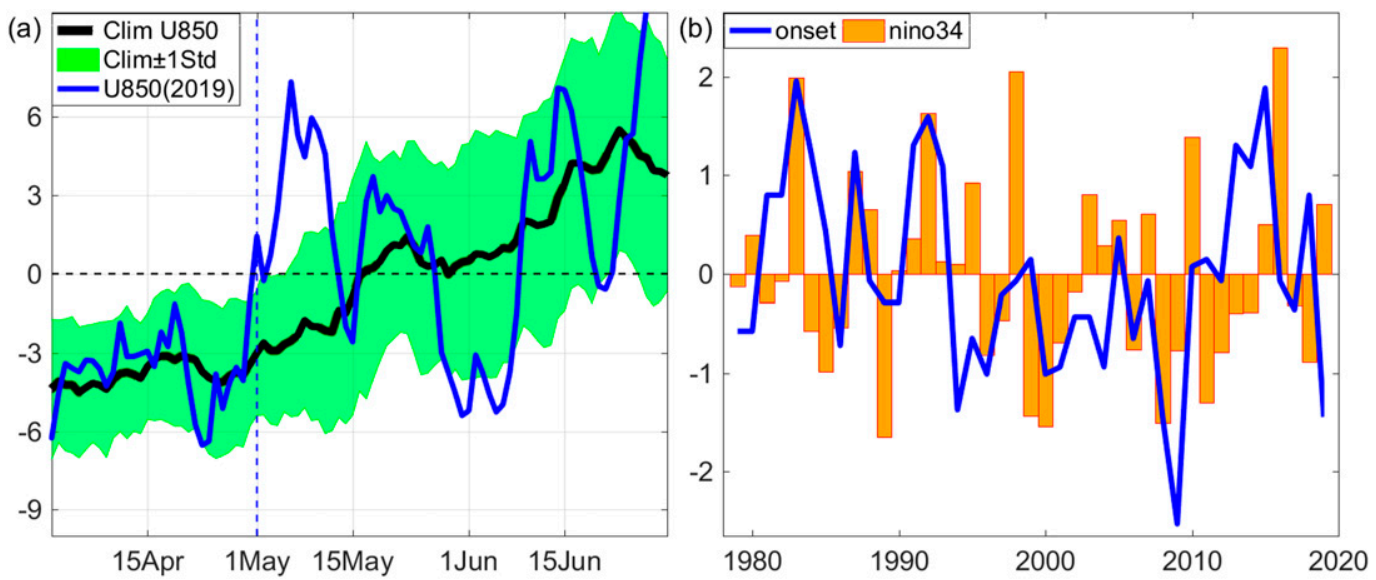

FIG. 1. (a) The climatology mean (black curve) and standard deviation (green background) of 850-hPa zonal wind (units in $\mathrm{m} \mathrm{s}^{-1}$ ) over central SCS $\left(5^{\circ}-15^{\circ} \mathrm{N}, 110^{\circ}-120^{\circ} \mathrm{E}\right.$; rectangle in Fig. 9a) for $1979-2019$. The blue curve in (a) denotes $850-\mathrm{hPa}$ zonal wind averaged over central SCS in 2019. The vertical dashed line highlights the SCSSM onset date (i.e., 1 May) in 2019. (b) The normalized time series of the SCSSM onset date (blue curve) and the Niño-3.4 index in the preceding winter (bar).

(ERSSTv5), data (Huang et al. 2017) with a horizontal resolution of $2^{\circ} \times 2^{\circ}$. All the above datasets cover the analysis period of 1979-2019.

In addition, several indices are applied to reveal the oceanic and atmospheric conditions. As in previous studies (Chen et al. 2014, 2015, 2017), the Niño-3.4 index (SST anomalies averaged in the region of $5^{\circ} \mathrm{N}-$ $5^{\circ} \mathrm{S}, 120^{\circ}-170^{\circ} \mathrm{W}$ ) is used to depict the variability of ENSO. Following Liang et al. (2013), who investigated the relationship between SCSSM onset and the thermal condition of the western North Pacific warm pool (WNPWP), the WNPWP index is defined as the SST anomalies averaged in the domain of $\left(6^{\circ}-16^{\circ} \mathrm{N}, 130^{\circ}-170^{\circ} \mathrm{E}\right)$. The Real-time Multivariate MJO (RMM) indices (Wheeler and Hendon 2004) and the boreal summer intraseasonal oscillation (BSISO) indices (Lee et al. 2013) are used to depict the 30-60-day oscillation.

Following Wang et al. (2004), the SCSSM onset is regarded as the steady easterly to westerly shift of $850-\mathrm{hPa}$ zonal wind over the central SCS $\left(5^{\circ}-15^{\circ} \mathrm{N}\right.$, $\left.110^{\circ}-120^{\circ} \mathrm{E}\right)$. For the details of the objective criteria, the readers are referred to (Wang et al. 2004; Kajikawa and Wang 2012; Hu et al. 2018b). The SCSSM onset data for 1979-2016 is obtained from Hu et al. (2018b), while the onset date for recent years are 16 May 2017, 1 June 2018, and 1 May 2019.

The Morlet wavelet (Torrence and Compo 1998) was applied to examine the spectrum features, and the Butterworth bandpass filter (Murakami 1979; Qiao et al. 2015) was used to isolate the 30-60-day oscillation. The significance levels of the correlation coefficients and anomalies obtained from the composition analysis are estimated by a two-sided Student's $t$ test.

\section{Extremely early SCSSM onset in 2019 following an El Niño event}

a. Anomalies in 2019

As shown in Fig. 1a, the steady shift (Wang et al. 2004; Kajikawa and Wang 2012; Hu et al. 2018b) of low-level zonal wind in 2019 occurs on 1 May, which is an extremely early SCSSM onset. Such an abrupt change in low-level circulation is accompanied by a sharp decrease in the OLR (figure not shown). Compared to the mean onset date of 21 May, the SCSSM onset in 2019 was advanced by 20 days, which is only second to 2009 and identical to 2008 in occurrence (Hu et al. 2018b). The early onset of the SCSSM in 2008 and 2009 may be largely due to the preceding winter La Niña events (Fig. 1b). In contrast, the winter of 2018-19 is controlled by an El Niño event (Guo et al. 2019; Fig. 1b) with a Niño-3.4 index of $0.8^{\circ} \mathrm{C}$. While ENSO has long been regarded as one of the most prominent predictors for SCSSM onset (Zhu and Li 2017; Martin et al. 2019), their in-phase relationship seems to have changed in recent years, especially in 2018 (Liu and Zhu 2019) and 2019 (Fig. 1). A recent weakening relationship between ENSO and the onset of SCSSM will be further discussed later.

Numerous studies indicate that the anomalous anticyclone over the WNP is the key circulation system that bridges El Niño events and the East Asia climate (Wang et al. 2000; Xie et al. 2009, 2016; Wang et al. 2012; Zhang et al. 2017; Li et al. 2017 and references therein). 

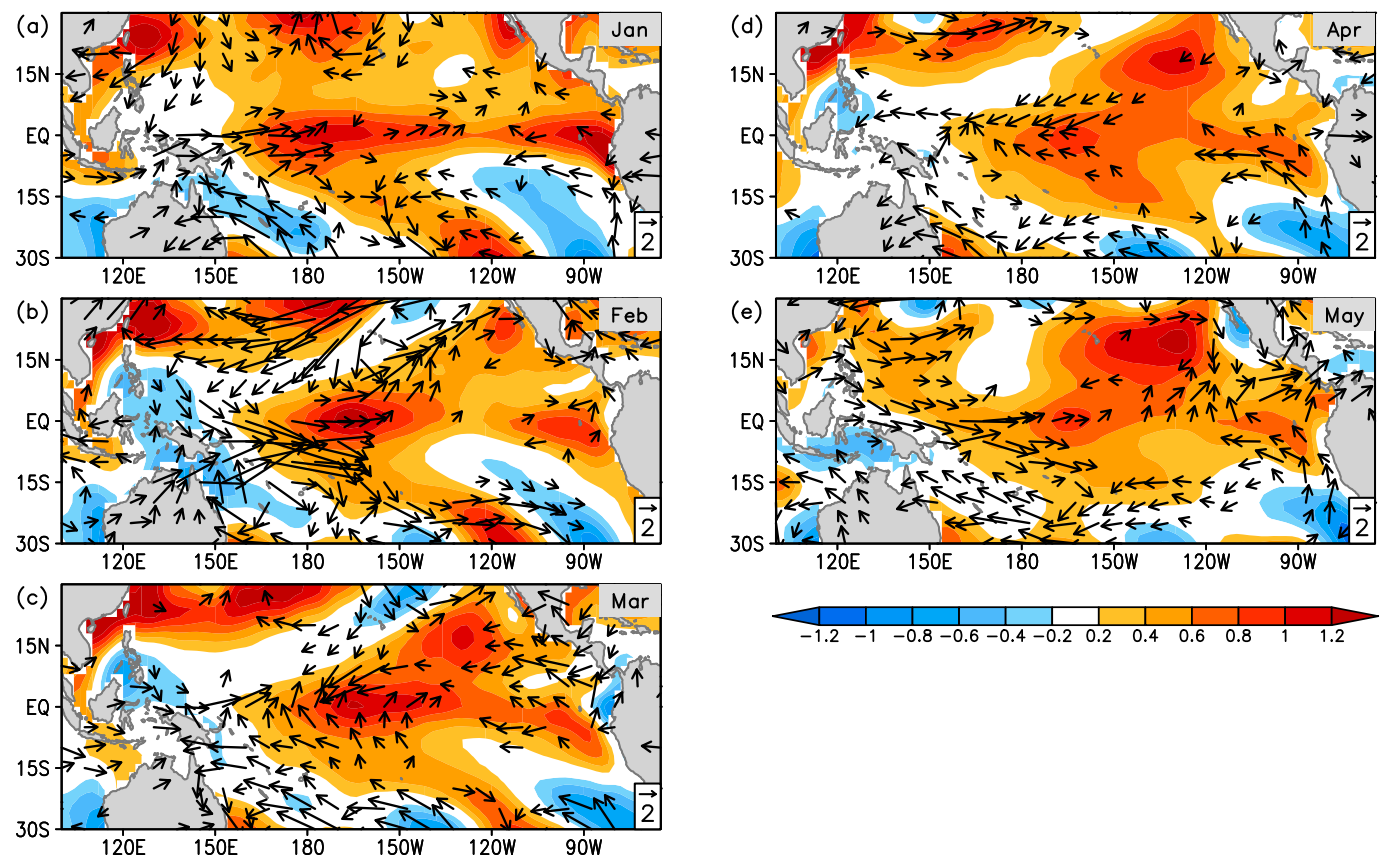

FIG. 2. The anomalous SST and 850-hPa winds in (a) January, (b) February, (c) March, (d) April, and (e) May 2019 (compared to the climatology of 1979-2019). Wind speeds less than $1.5 \mathrm{~m} \mathrm{~s}^{-1}$ are masked.

Figure 2 shows the time evolution (from January to May) of the anomalous SST and low-level wind in 2019, while the anomalous anticyclone dominates the northern SCS and Philippine Sea during January and February (Figs. 2a,b; Guo et al. 2019) but is absent in March (Fig. 2c). Moreover, an anomalous cyclone appears to the east of Taiwan in May (Fig. 2e), and the anomalous westerly winds to the south flank of this cyclone signify an extremely early SCSSM onset in 2019 (Fig. 1). For the oceanic conditions, the cold SST anomalies around the Philippine Sea are rather weak during the preceding winter and early spring. In May 2019, the SST over the WNP is even warmer than the climatology, which corresponds well with the lowlevel anomalous cyclone.

Previous studies suggest that the anomalous anticyclone over the WNP associated with an El Niño event can be largely understood as a Rossby wave-type atmospheric response (Matsuno 1966; Gill 1980) to the local suppressed latent heating and oceanic surface cooling over the WNP (e.g., Zhang et al. 1996; Wang et al. 2000). In addition, the northeasterly wind anomalies to the east flank of the anomalous anticyclone enhance the climatological northeasterly winds, which could help to maintain local SST cooling over the WNP via enhancing surface evaporation and upward surface heat fluxes (Xie and Philander 1994; Wang et al. 2000). Notably, SST anomalies over the Indian Ocean and North Atlantic are also important in maintaining the
El Niño-related anticyclonic anomaly over the WNP from winter to the following summer (Xie et al. 2009; Rong et al. 2010). The disappearance of an anomalous anticyclone in late spring of 2019 over the WNP following the 2018/19 El Niño event is closely related to the SST anomalies over the WNP, which is examined in Fig. 3. As showed in Figs. 3a and 3d, for the ENSO composited SST anomalies there usually appears a horseshoe shape SST cooling anomaly pattern over the tropical WNP in the preceding winter and spring. Although the amplitude of these cold SST anomalies is much weaker than that of the warm SST anomalies over the equatorial central-eastern Pacific, the impact of cooling in the warm pool cannot be overlooked. This is because the convection activities depend on total SST (rather than SST anomalies), and thus, the atmosphere is very sensitive to SST anomalies in the warm pool region (e.g., Wang et al. 2000). However, in the case of 2019, prominent warming appears over the equatorial central and eastern Pacific, and the SST anomalies over the WNP are largely different from the ENSO composited results (Figs. 3a,b,d,e). Namely, cold SST anomalies over the WNP are very weak and confined to be located near a small patch over the southern SCS and Philippine Sea (Fig. 3b) in the preceding winter. Such cold SST anomalies may be linked to the anomalous anticyclone shown in Figs. 2a and 2b, which resulted in an extraordinary long wet spell in the south of the Yangtze River in the winter of 2018/19 (Guo et al. 2019). In the late spring of 

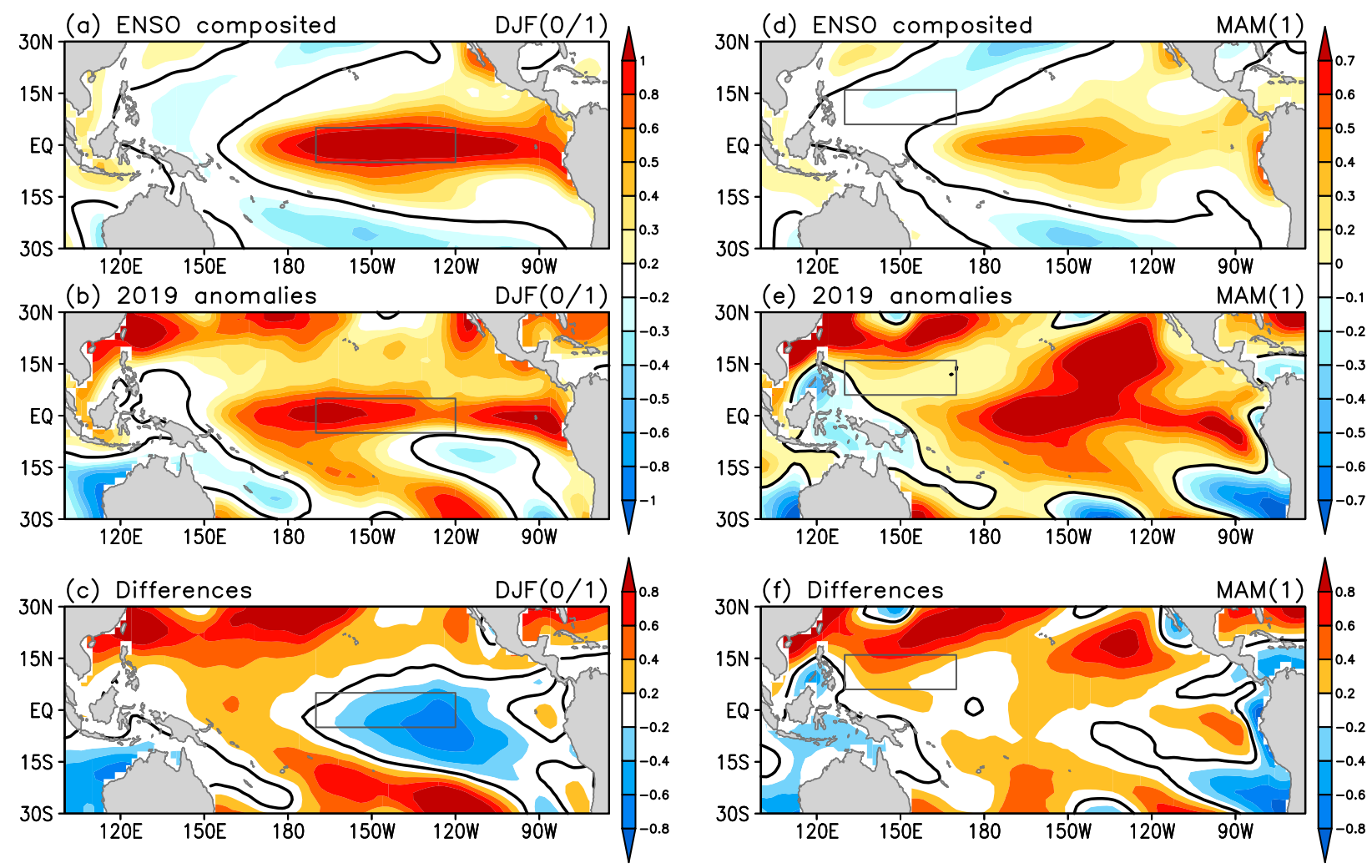

FIG. 3. (a) Composited anomalies of SST in $\mathrm{D}(0) \mathrm{JF}(1)$ between El Niño and La Niña events. The time notations of " 0 " and " 1 " represent ENSO developing and decaying years, respectively. The composited differences are obtained by El Niño minus La Niña and then divided by 2. (b) SST anomalies in the preceding winter of 2019 relative to the climatology of 1979-2019; (c) the difference between (b) and (a), which denotes the difference between 2019 and the ENSO composited results; and (d)-(f) as in (a)-(c), but for the MAM(1). The zero lines are thickened. The rectangles in (a)-(c) and (d)-(f) denote the Niño-3.4 region $\left(5^{\circ} \mathrm{N}-5^{\circ} \mathrm{S}, 120^{\circ}-170^{\circ} \mathrm{W}\right)$ and western North Pacific warm pool region $\left(6^{\circ}-16^{\circ} \mathrm{N}, 130^{\circ}-170^{\circ} \mathrm{E}\right)$, respectively.

2019, negative SST anomalies were confined to the SCS and Maritime Continent, and the tropical WNP are dominated by warm SST anomalies (Figs. 2e and 3e). These warm SST anomalies induce a cyclonic anomaly over the WNP via a Rossby wave-type atmospheric response (Figs. 2e and 3e) and result in an extremely early SCSSM onset. The differences between the case of 2019 and the ENSO composited results are further highlighted in Figs. 3c and 3f. Compared to the ENSO composited results, the SST is warmer in the western Pacific and colder in the eastern Pacific during the preceding winter of 2019. This phenomenon has already been investigated by a recent paper of Johnson et al. (2019), who reported that the anomalous SST gradient in the western and central Pacific can partly offset canonical El Niño impacts. In the late spring of 2019, the SST over the WNP is basically warmer than the ENSO composited results, except for a small region over the southern SCS. This warm SST in the WNP (Figs. 3e,f) may result in the absence of an anomalous anticyclone and the appearance of an anomalous cyclone over the
WNP (Fig. 2e). It needs to be mentioned that an anomalous cyclone could also reinforce warm SST anomalies (e.g., Wang et al. 2000). The circulation and SST anomalies over the WNP are strongly coupled with each other via a positive air-sea feedback (e.g., Xie and Philander 1994; Wang et al. 2000), which is different from the pure cause-and-effect relationship in the Matsuno-Gill model (Matsuno 1966; Gill 1980).

To further illustrate the above anomalous SST background, Fig. 4 shows the evolution of the composited SST anomalies in the Niño-3.4 region and the WNPWP region. The associated evolution of SST in 2019 is also presented in Fig. 4 to facilitate a comparison. Consistent with previous studies (Wang et al. 2000; Zhang et al. 2017; Li et al. 2017), warm SST anomalies in the Niño-3.4 region peak in winter and decay in the following spring and summer. However, the warm SST anomalies in the tropical central-eastern Pacific remain strong during the spring and summer of 2019. This suggests that the decay of the 2018/19 El Niño event is slower. A previous study also demonstrated that fast decaying 


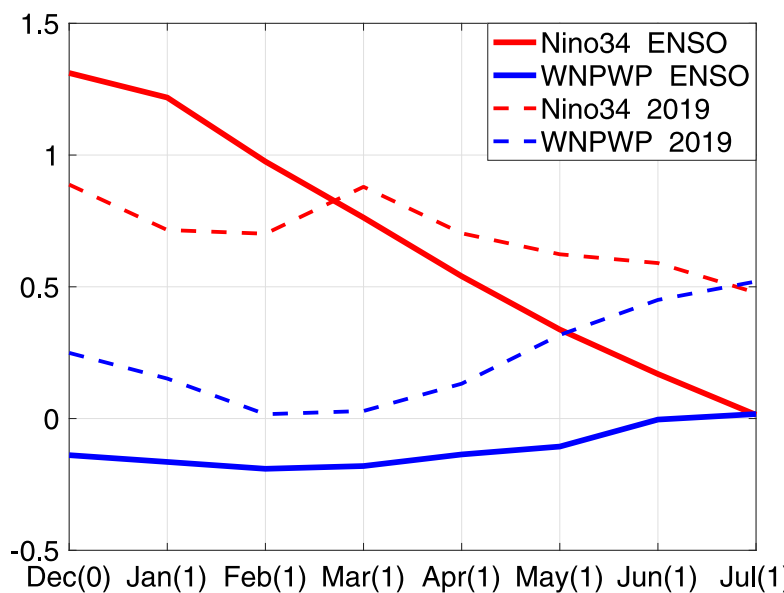

FIG. 4. Evolutions of composited SST anomalies (units in ${ }^{\circ} \mathrm{C}$ ) in the Niño-3.4 region $\left(5^{\circ} \mathrm{N}-5^{\circ} \mathrm{S}, 120^{\circ}-170^{\circ} \mathrm{W}\right.$; red solid line) and western North Pacific warm pool region $\left(6^{\circ}-16^{\circ} \mathrm{N}, 130^{\circ}-170^{\circ} \mathrm{E}\right.$; blue solid line) from $\operatorname{Dec}(0)$ to Jul(1) between El Niño and La Niña events. The composited differences are obtained by El Niño minus La Niña and then divided by 2 . The anomalies of 2019 are also shown in the dashed curves.

El Niño events can induce a stronger anticyclone anomaly in the following spring-summer over the western North Pacific compared to slow decaying El Niño events (Chen et al. 2012). In addition, SST anomalies in the warm pool during 2019 are largely different from the composited results and are even warmer than the climatology (Fig. 4). The abnormal SST over the WNPWP region may explain the absence of an anticyclone in 2019, which does not prevent monsoon onset as the composited results.

\section{b. The role of the 30-60-day oscillation}

To analyze the onset process of SCSSM in 2019, the anomalous zonal wind at $850 \mathrm{hPa}$ is shown in Fig. 5a. The zonal wind anomalies in March and April are very weak (see also Figs. 2c,f), while the anomalous westerly dominates throughout May. The wavelet spectrum in Fig. 5b shows that, before and during the SCSSM onset, a prominent 30-60-day oscillation appears, while the enhancement of quasi-biweekly oscillation mainly occurs after monsoon onset. Thus, the 30-60-day oscillation may be one important contributor for SCSSM onset in 2019. Figure 5a also shows a monsoon onset consisting of an easterly to westerly shift of the 30-60-day oscillation. Namely, both the time domain and frequency domain analyses suggest that the 30-60-day oscillation plays an important role in the SCSSM onset of 2019

Figure 6 shows the 5-day sequence of the 30-60-day bandpass-filtered OLR and low-level wind anomalies, which depict the propagation and evolution of the

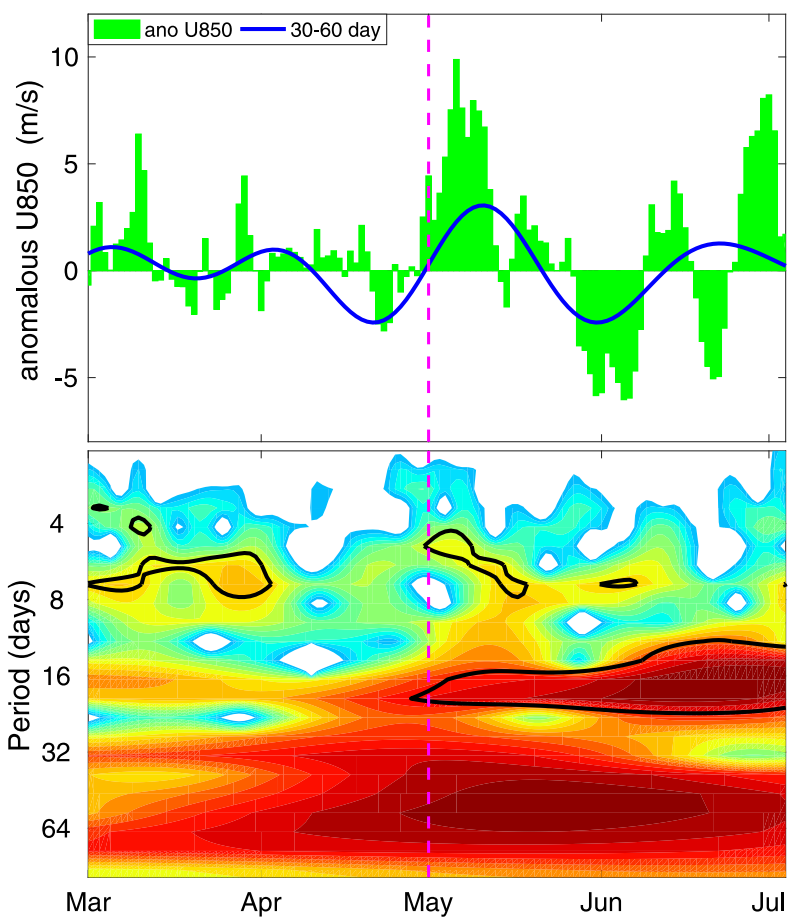

FIG. 5. (a) 850-hPa zonal wind anomalies (units in $\mathrm{m} \mathrm{s}^{-1}$ ) averaged over central SCS in 2019 relative to the climatology (bar). The curve denotes the 30-60-day oscillation component of the $850-\mathrm{hPa}$ zonal wind anomalies. (b) The Morlet wavelet spectrum of the regional mean 850 -hPa zonal wind anomalies over SCS. The black lines denote the $95 \%$ confidence level. Vertical dashed lines denote the SCSSM onset date in 2019 (1 May).

intraseasonal oscillation. On 15 April, enhanced convection appeared over the equatorial central Indian Ocean (Fig. 6a). To the west of the enhanced convection, two anomalous cyclones appear over the northern and southern tropical Indian Ocean, which is the Rossby wave-type atmospheric response to diabatic heating (Matsuno 1966; Gill 1980). In the following days (Figs. 6b-d), the enhanced convection propagated northeastward. When the negative OLR anomalies and the accompanying anomalous cyclone intrudes into BOB (Fig. 6d) and the SCS (Fig. 6e), they trigger the onset of the summer monsoon. On 10 May, the BOB and SCS are dominated by a strong westerly wind, which signifies a robust monsoon onset (see also Figs. 1a and 8a). The results obtained from Fig. 6 confirmed that the SCSSM onset in 2019 is largely due to the northeastward propagating 30-60-day oscillation.

The vigorous northeastward propagating 30-60-day oscillation is also clearly reflected by the RMM indices (Wheeler and Hendon 2004) and BSISO1 indices (Lee et al. 2013), which is shown in Fig. 7. Using the RMM indices as an example, after the 20 April (Fig. 6b), the MJO became rather strong and its amplitude was 

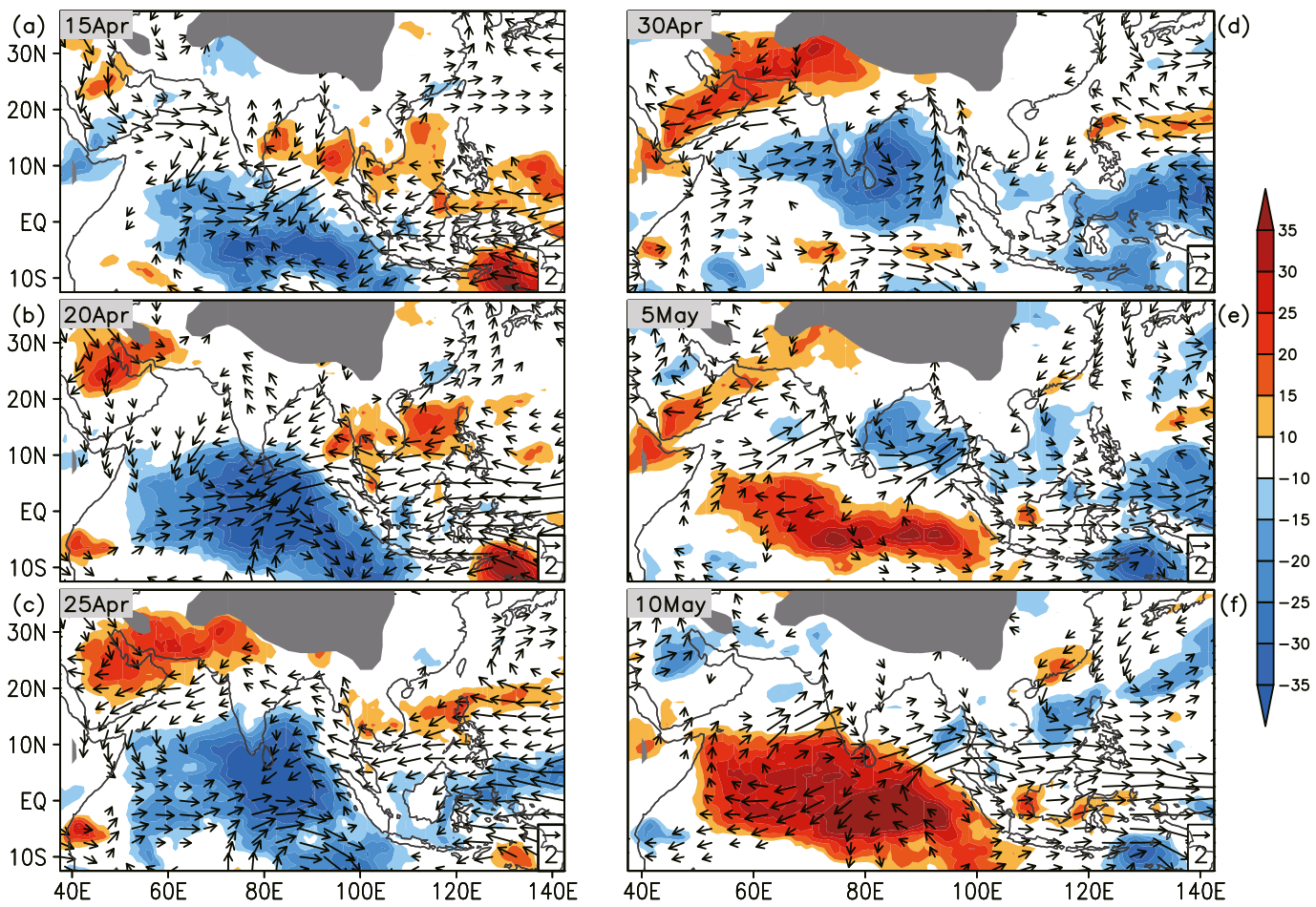

FIG. 6. The 30-60-day bandpass-filtered OLR (units in $\mathrm{W} \mathrm{m}^{-2}$ ) and $850-\mathrm{hPa}$ wind (units in $\mathrm{m} \mathrm{s}^{-1}$ ) anomalies on (a) $15 \mathrm{Apr}$, (b) $20 \mathrm{Apr}$, (c) $25 \mathrm{Apr}$, (d) $30 \mathrm{Apr}$, (e) 5 May, and (f) 10 May 2019. The gray mask denotes the region higher than $1500 \mathrm{~m}$.

greater than 1 (i.e., out of the unit circle in the phase space) (Fig. 7a). In the following days, the MJO remained vigorous and propagated eastward. In phase 4 when MJO approaches the Maritime Continent it triggers the onset of the BOB summer monsoon. Two days later in phase 5, MJO further triggers SCSSM onset.
After that, the MJO continues its eastward journey (i.e., Figs. 1a and 7a). Moreover, the BSISO1 indices (Fig. 7b) are considered more suitable in depicting the northward propagating intraseasonal oscillations in the boreal summer (Lee et al. 2013), which is generally consistent with the results of the RMM indices (Figs. 7a,b).
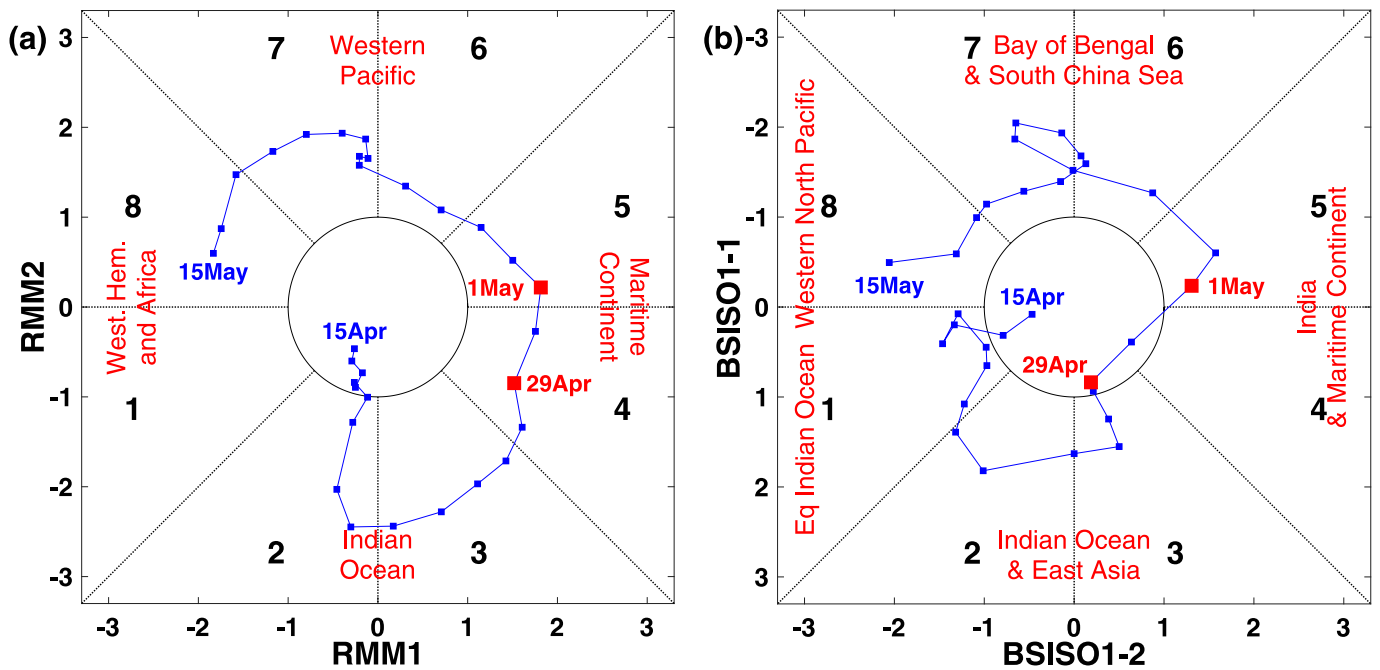

FIG. 7. (a) RMM (Wheeler and Hendon 2004) and (b) BSISO1 (Lee et al. 2013) indices phase plots for the 30- to 60-day oscillation in 2019 that triggers the onset of SCSSM. 
For the mechanisms, previous studies suggest that the MJO or the 30-60-day oscillation modulates the SCSSM onset mainly by inducing a large-scale easterly/westerly wind shift (e.g., Tong et al. 2009; Hu et al. 2018a). This mechanism also seems to work in the case of 2019 as revealed by the 30-60-day filtered zonal wind anomalies over the SCS (Figs. 5a and 6). However, statistically, the SCSSM onset tends to occur when the convective active phases (i.e., phases 4-6) of the 3060-day oscillation are located around the SCS (Lin et al. 2016; $\mathrm{Hu}$ et al. 2019). While the MJO could modulate the monsoon onset by creating a favorable environment, the direct triggers for SCSSM onset are generally associated with some synoptic-scale systems related to the MJO, which is investigated in the following.

\section{c. The roles of the monsoon onset vortex and cold front}

Figure 6 suggests that when the 30-60-day oscillation intrudes into the BOB it leads to enhanced convection as well as large-scale circulation changes. As shown in Fig. 8, the onset of the BOB summer monsoon (Yu et al. 2012) occurs on 29 April, although the enhanced convection appears much earlier than the zonal wind shift. On 29 April, two cyclones appeared over the Northern and Southern Hemisphere, which were regarded as "twin cyclones" or "double cyclones" mentioned in previous studies (e.g., Lau et al. 1998, 2000; Ding et al. 2004). The cyclone in the Northern Hemisphere is also called a "monsoon onset vortex" (Krishnamurti et al. 1981; Krishnakumar et al. 1993; Liu et al. 2002; Wu et al. 2005,2012 ) because this tropical cyclone is important in triggering the onset of the Asian summer monsoon.

Although the summer monsoon was established over the BOB on 29 April, the SCS is still dominated by easterly wind and anticyclonic circulation (Fig. 8b). Two days later, westerly wind prevailed over the SCS (Fig. 9a), which signified the SCSSM onset. Previous studies revealed that the monsoon onset vortex and the associated condensation heating over the $\mathrm{BOB}$ is an important trigger for the onset of SCSSM. According to Liu et al. (2002) and Wu et al. (2005), the BOB monsoon onset vortex can cause the development of low-level westerly and associated moisture advection over the northern SCS, which triggers the onset of SCSSM. In addition, the Rossby wave train is excited by condensation heating over the BOB and facilitates the southward intrusion of cold air, which is also an important trigger for the onset of SCSSM. It is important to note that in Fig. 8b, cyclonic circulation and enhanced convection, which are related to a midlatitude cold front, appear around the Yellow Sea. (a) OLR \& U850 over Bay of Bengal

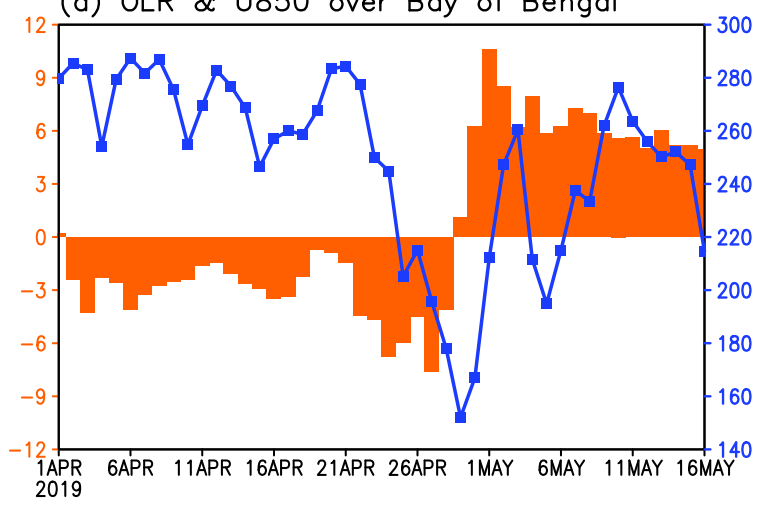

(b) OLR \& Wind850 on $29 \mathrm{Apr}$

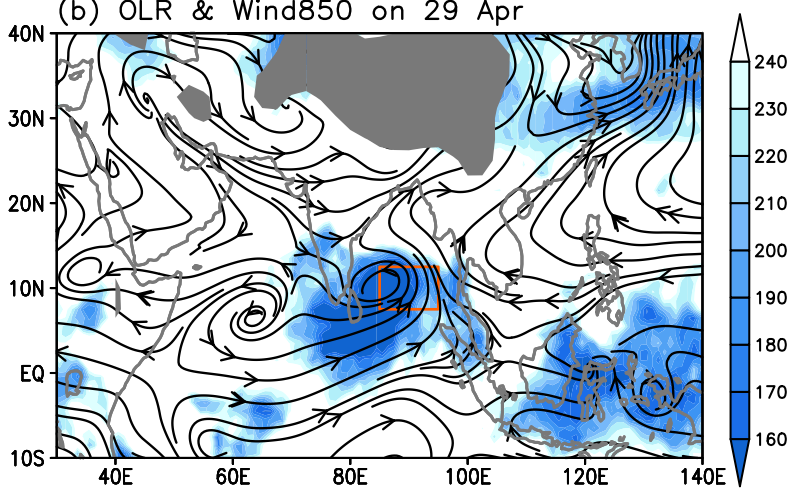

FIG. 8. (a) Time series of the region-mean OLR (units in $\mathrm{W} \mathrm{m}^{-2}$ ) and $850-\mathrm{hPa}$ zonal wind (units in $\mathrm{m} \mathrm{s}^{-1}$ ) over the BOB [7.5०$12.5^{\circ} \mathrm{N}, 85^{\circ}-95^{\circ} \mathrm{E}$; see rectangle in (b)]. The BOB summer monsoon onset (Yu et al. 2012) in 2019 occurs on 29 Apr. (b) OLR and wind at $850 \mathrm{hPa}$ on 29 Apr 2019. The gray mask denotes the region higher than $1500 \mathrm{~m}$.

On the day of SCSSM onset (1 May), this cold front was markedly enhanced, which extends from Japan to southern China (Fig. 9a as revealed by the wind shear line). Cyclonic and anticyclonic centers are observed over northeast Asia and eastern China, respectively (Fig. 9a). The resultant strong northerly wind between them advected cold air southward (Fig. 9a). The southward intrusion of this cold air can be clearly seen in the latitude-time cross section of temperature at $850 \mathrm{hPa}$ averaged over $110^{\circ}-120^{\circ} \mathrm{E}$ (Fig. 9b), which is similar to the case in 1998 (Ding and Liu 2001). While the BOB monsoon onset vortex may partly contribute to the cold front (Liu et al. 2002), it is speculated that the primary cause of this cold front is the trough in the mid- to upper troposphere. As shown in Fig. 10, an alternating troughridge-trough appears at 200 and $500 \mathrm{hPa}$ over the Asian continent. The upper-level ridge and trough are located to the west of the low-level anticyclone and cyclone, which may create a favorable condition for the development of a cold front (e.g., Bluestein 1993; Holton and Hakim 2013). 
(a) Wind850 \& Air850 on 1 May

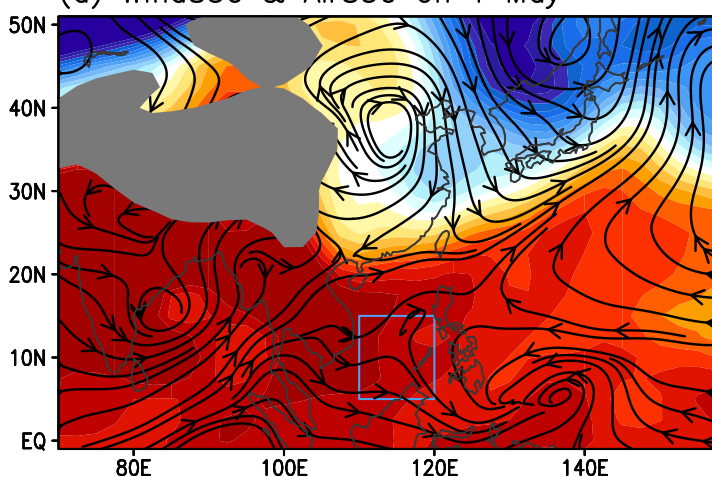

(b) Air850 cross section

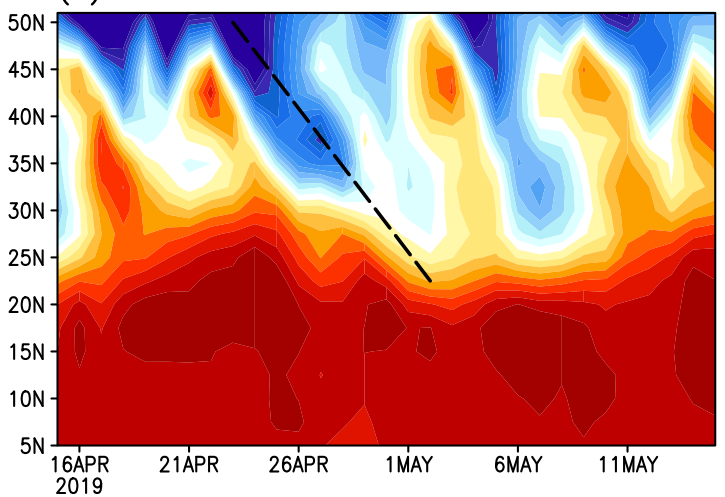

FIG. 9. (a) Temperature (units in ${ }^{\circ} \mathrm{C}$ ) and wind (units in $\mathrm{m} \mathrm{s}^{-1}$ ) at $850 \mathrm{hPa}$ on 1 May 2019. The rectangle highlights the central SCS $\left(5^{\circ}-15^{\circ} \mathrm{N}, 110^{\circ}-120^{\circ} \mathrm{E}\right)$. The gray mask denotes the region higher than $1500 \mathrm{~m}$. (b) The latitude-time cross section of the temperature at $850 \mathrm{hPa}$ averaged over $110^{\circ}-120^{\circ} \mathrm{E}$. The dashed line denotes the southward intrusion of cold air.

The mechanisms for the cold front in the low-level and the trough in the upper level to trigger the onset of SCSSM have been summarized by Ding and Liu (2001), which includes the following: 1) a lifting effect and the occurrence of rainfall (see also Li et al. 2016), 2) increasing the shear vorticity of the wind shear line (Fig. 9a), 3) enhancing the baroclinicity and providing available potential energy (Fig. 9b), and 4) forcing the subtropical high to retreat southward and eastward (Fig. 10b). In addition, numerous studies have revealed that a cold front is an important trigger of the onset of SCSSM (e.g., Chang and Chen 1995; Ding and Liu 2001; Tong et al. 2009; Kueh and Lin 2010; Huangfu et al. 2018) although its impacts may be confined to the northern SCS (Tong et al. 2009). In summary, under the favorable environment of convective active and the westerly phase of the 30-60-day oscillation, the collaboration of the monsoon onset vortex over the Bay of Bengal and the cold front associated with the midlatitude trough eventually triggers the onset of SCSSM in 2019. It should be mentioned that although the TCs are

\section{(a) HGT200* \& Wind200 on 1 May}

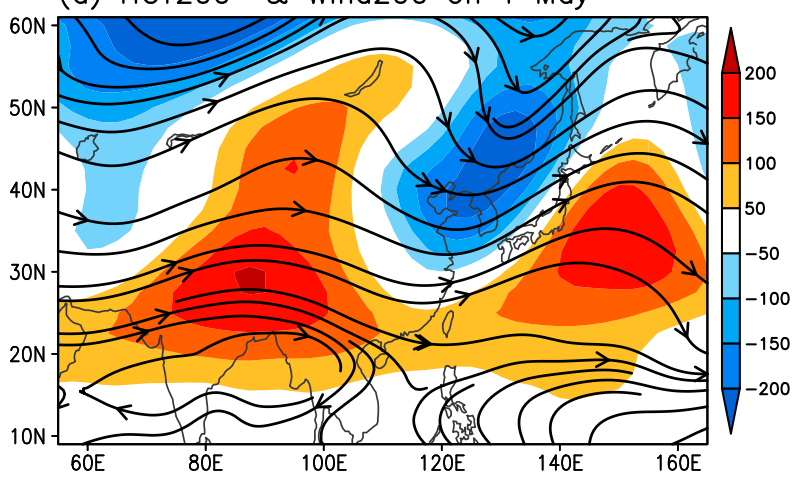

(b) HGT500* \& Wind500 on 1 May

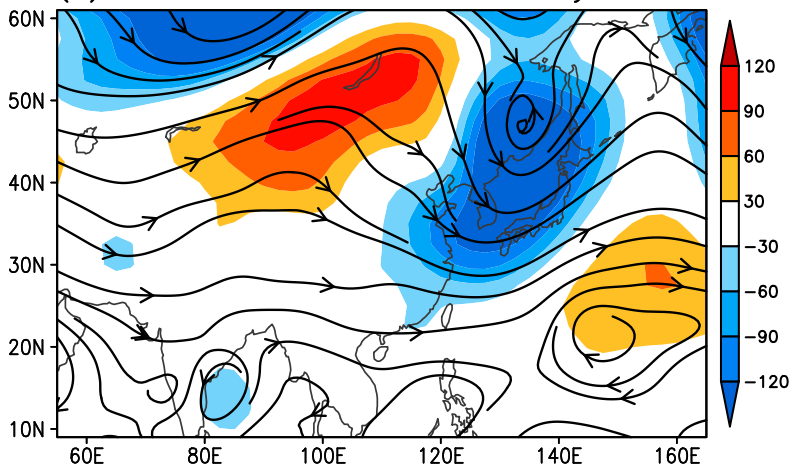

FIG. 10. Anomalies of geopotential heights (units in $\mathrm{m}$ ) and wind (units in $\mathrm{m} \mathrm{s}^{-1}$ ) at (a) $200 \mathrm{hPa}$ and (b) $500 \mathrm{hPa}$ on 1 May 2019. The zonal mean has been removed from the geopotential heights to highlight the ridge and trough in the mid- to upper troposphere.

possibly another prominent contributor for the onset (Mao and Wu 2008; Kueh and Lin 2010; Kajikawa and Wang 2012; Chen 2015; Huangfu et al. 2017), no TC activities appear over the WNP in throughout April and May; thus they did not contribute to the SCSSM onset in 2019.

\section{Summary and discussion}

Predicting the timing of SCSSM onset is important for agriculture and planting in East Asia. While ENSO has long been regarded as the most important predictor for SCSSM onset, the relationship has changed in recent years, especially when an extremely early SCSSM onset occurs following an El Niño event in 2019. Based on NCEP-DOE reanalysis, OLR, and ERSSTv5 data, the process of the second earliest SCSSM onset of the past 41 years (Fig. 1) was investigated. The related processes are summarized in Fig. 11. The absence of cold SST anomalies in the Philippine Sea following the 2018/19 El Niño event (Figs. 3 and 4) may be responsible for the absence of anomalous anticyclone over the WNP (Fig. 2). Thus, the circulation in late spring of 2019 does 


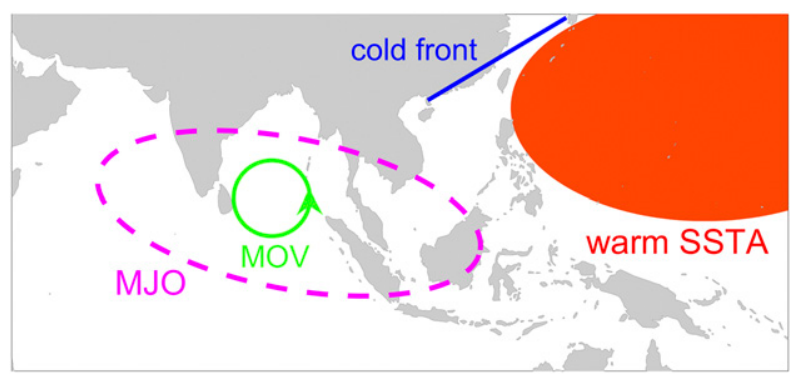

FIG. 11. Schematic diagram for the extremely early SCSSM onset in 2019 following an El Niño event. The anomalous warm SST anomalies over the subtropical WNP may explain the absence of the anomalous anticyclone over the Philippine Sea, which is different from the canonical El Niño decaying spring. The convective active and westerly phase of the 30-60-day oscillation creates a favorable environment for the monsoon onset. The collaboration of the MOV (monsoon onset vortex) and midlatitude front eventually triggers the SCSSM onset.

not prevent SCSSM onset, which is different from the composited result of the El Niño decay years. In addition, the vigorous 30-60-day oscillation creates a favorable environment for SCSSM onset when its convective active and westerly phase approaches the Maritime Continent (Figs. 5-7). Under this favorable environment, the monsoon onset vortex over the BOB (Fig. 8) and the cold front associated with a midlatitude trough (Figs. 9 and 10) act as direct triggers for the onset of SCSSM. No TC activities were observed over the WNP during April and May, and the enhancement of the quasibiweekly oscillation occurs after the monsoon onset and contributed little to the SCSSM onset in 2019.

The background of this study is the weakening relationship between the SCSSM onset and ENSO. Figure 12a shows 13-yr running correlations between the monsoon onset date and the Niño-3.4 index in the preceding winter, which exhibited substantial weakening, especially in recent years. The results are similar when using other running windows (e.g., 11 and 15 years). This phenomenon is further highlighted in Fig. 12b, which shows the 13-yr running correlation of the monsoon onset date with SST in the equatorial Pacific of the previous winter. The significant positive correlations in the eastern Pacific gradually shift westward to the central Pacific, while the marked negative correlations in the western Pacific disappear after the mid-2000s. The spatial patterns of SST anomalies that were associated with the SCSSM onset are then separately studied for these two periods. For the epoch of (a) CORR: SCSSM \& Nino34

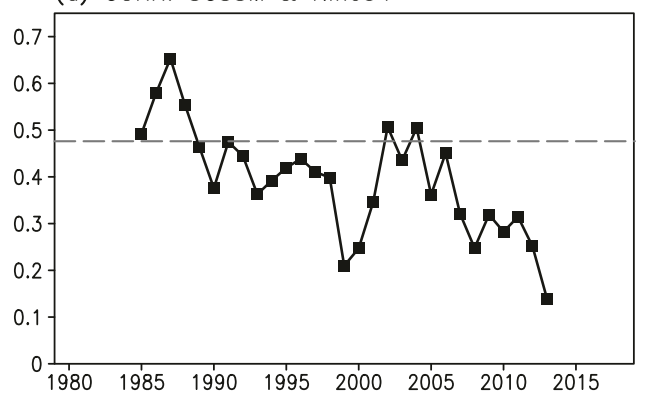

(b) CORR: SCSSM \& SST(5S-5N)

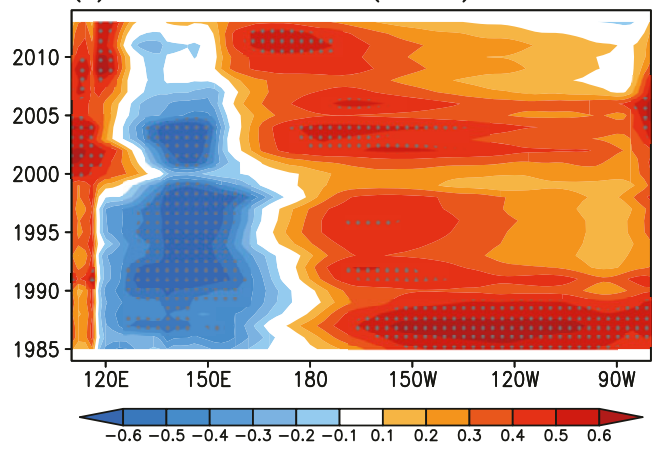

(c) CORR: 1979-2004

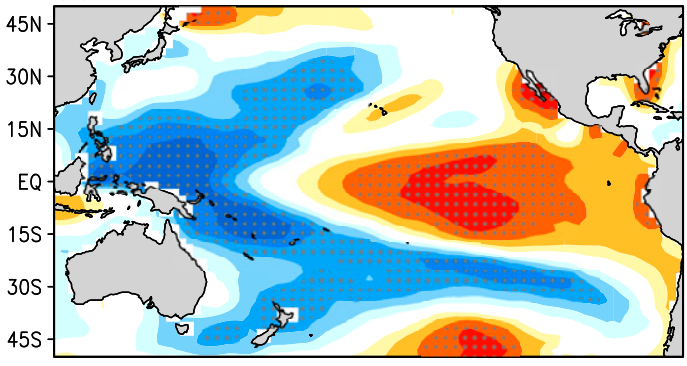

(d) CORR: 2005-2019

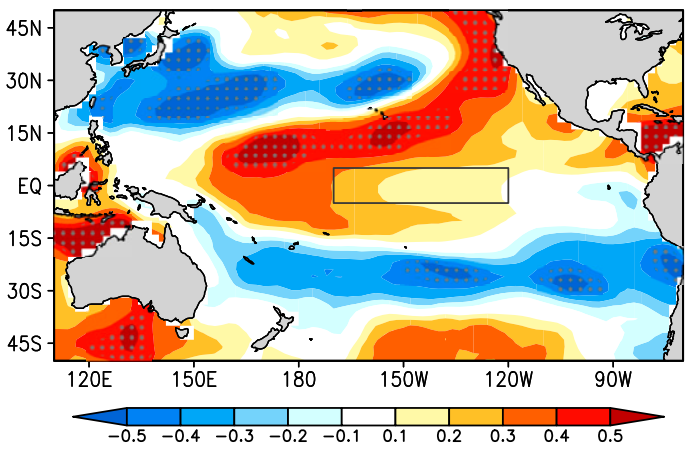

FIG. 12. (a) The 13-yr running correlation of the SCSSM onset date with the Niño-3.4 index in the preceding winter (Fig. 1b). (b) The 13-yr running correlation of the SCSSM onset date with the equatorial $\left(5^{\circ} \mathrm{S}-5^{\circ} \mathrm{N}\right.$ average) SST in the preceding winter. Years in (a) and (b) correspond to the central years of the 13-yr running window. The correlation patterns of the SCSSM withdrawal date with the SST in the preceding winter for the periods of (c) 19792004 and (d) 2005-19. The rectangle in (d) denotes the Niño-3.4 region. The dotted areas indicate that the correlations are significant at the $90 \%$ confidence level. 
1979-2004, the correlation pattern between SCSSM onset and winter SST resembles the canonical El Niño pattern with a significant positive correlation in the central-to-eastern tropical Pacific and a negative correlation in the western Pacific extending northeastward and southeastward to the subtropical Pacific. However, for the epoch of 2005-19, the positive correlation in the Niño-3.4 region became much weaker and insignificant, while a dipole mode of SST anomalies appears in the western Pacific. Interestingly, there was a significant negative correlation over the subtropical western Pacific (i.e., to the East of Taiwan), which became more important for SCSSM onset in recent years. In particular, the anomalous warm SST appears over this region (Fig. 2) before the extremely early SCSSM onset in 2019, which confirms this out-of-phase relationship. This correlation pattern remains robust even if we exclude the case of 2019 (i.e., the correlation for the period from 2005 to 2018). Namely, although the impact of ENSO on SCSSM onset seems to be weakening, the linkage between monsoon onset and subtropical WNP SST anomalies are strengthening.

The weakening relationship between ENSO and monsoon onset suggests that using ENSO as a predictor (Zhu and Li 2017; Martin et al. 2019) for the prediction of SCSSM onset may have failed in recent years like 2018 (Liu and Zhu 2019) and 2019 (Fig. 1b). Thus, other possible factors, such as land-sea thermal contrast (e.g., Liu et al. 2010; Li et al. 2020) and Indian Ocean (e.g., Yuan et al. 2008; Liu et al. 2016), should be emphasized in the seasonal prediction of SCSSM onset. As pointed out by Zhu and Li (2017), SCSSM onset is affected by both the interannual and intraseasonal mode. While the interannual mode may be linked to SST anomalies such as ENSO (Zhu and Li 2017; Martin et al. 2019), the intraseasonal oscillations (Shao et al. 2015; Zhu and Li 2017; Wang et al. 2018) also plays an important role in the variability of SCSSM onset. A recent paper by Lin et al. (2016) revealed that the years that are inconsistent between the SCSSM onset and SST signal are basically due to the influences of MJO and the cyclone circulation over the Bay of Bengal. Thus, the extended-range forecast of the SCSSM onset (e.g., Zhu and $\mathrm{Li}$ 2017), which emphasizes the intraseasonal evolution processes, is also very important.

The ISO and synoptic-scale systems do not occur independently; actually, they are strongly and nonlinearly coupled. On the one hand, the ISO can modulate the embedded higher-frequency perturbations via barotropic energy conversion. On the other hand, the synoptic-scale systems can also strongly feedback to the ISO (e.g., Li 2014; Wang and Kajikawa 2015; Li and Zhou 2015). As shown in the case of 2019 and many other cases (e.g., Mao and Wu 2008; Kajikawa and Wang 2012; Wang and
Kajikawa 2015), the SCSSM onset processes are often accompanied by ISO and the embedded synoptic perturbations. Thus, it is hard to evaluate their relative contributions due to the intrinsic interplay among them (Wang and Kajikawa 2015 and references therein).

Acknowledgments. We thank the two anonymous reviewers for their valuable comments and suggestions, which led to a significant improvement in the manuscript. This study was jointly supported by the National Key Research and Development Program of China (Grant 2016YFA0600604), the National Natural Science Foundation of China (Grant 41721004), and the Chinese Academy of Sciences Key Research Program of Frontier Sciences (QYZDY-SSW-DQC024). Peng Hu would like to thank Mingmei Xie of the South China Sea Institute of Oceanology and Shaorou Dong of the Climate Center of Guangdong Province for helpful advice and several discussions. The authors declare no potential conflicts of interests.

\section{REFERENCES}

Bluestein, H. B., 1993: Synoptic-Dynamic Meteorology in Midlatitudes. Vol. II, Observations and Theory of Weather Systems, Oxford University Press, 606 pp.

Chang, C., and G. T. Chen, 1995: Tropical circulations associated with southwest monsoon onset and westerly surges over the South China Sea. Mon. Wea. Rev., 123, 3254-3267, https://doi.org/ 10.1175/1520-0493(1995)123<3254:TCAWSM>2.0.CO;2.

Chen, G., 2015: Comments on "Interdecadal change of the South China Sea summer monsoon onset." J. Climate, 28, 9029-9035, https://doi.org/10.1175/JCLI-D-14-00732.1.

Chen, L., C. Zhu, W. Wang, and P. Zhang, 2001: Analysis of the characteristics of 30-60 day low-frequency oscillation over Asia during 1998 SCSMEX. Adv. Atmos. Sci., 18, 623-638, https://doi.org/10.1007/s00376-001-0050-0.

Chen, S., B. Yu, and W. Chen, 2014: An analysis on the physical process of the influence of AO on ENSO. Climate Dyn., 42, 973-989, https://doi.org/10.1007/s00382-012-1654-z.

,,-- and -2015 : An interdecadal change in the influence of the spring Arctic Oscillation on the subsequent ENSO around the early 1970s. Climate Dyn., 44, 1109-1126, https:// doi.org/10.1007/s00382-014-2152-2.

—, W. Chen, and B. Yu, 2017: The influence of boreal spring Arctic Oscillation on the subsequent winter ENSO in CMIP5 models. Climate Dyn., 48, 2949-2965, https://doi.org/10.1007/ s00382-016-3243-z.

Chen, T.-C., and J.-M. Chen, 1995: An observational study of the South China Sea monsoon during the 1979 summer: Onset and life cycle. Mon. Wea. Rev., 123, 2295-2318, https://doi.org/ 10.1175/1520-0493(1995)123<2295:AOSOTS > 2.0.CO;2.

Chen, W., J. K. Park, B. Dong, R. Lu, and W. S. Jung, 2012: The relationship between El Niño and the western North Pacific summer climate in a coupled GCM: Role of the transition of El Niño decaying phases. J. Geophys. Res., 117, D12111, https://doi.org/10.1029/2011JD017385.

Ding, Y., 2007: The variability of the Asian summer monsoon. J. Meteor. Soc. Japan, 85B, 21-54, https://doi.org/10.2151/jmsj.85B.21. 
, and Y. Liu, 2001: Onset and the evolution of the summer monsoon over the South China Sea during SCSMEX field experiment in 1998. J. Meteor. Soc. Japan, 79, 255-276, https:// doi.org/10.2151/jmsj.79.255.

- , and J. Chan, 2005: The East Asian summer monsoon: An overview. Meteor. Atmos. Phys., 89, 117-142, https://doi.org/ 10.1007/s00703-005-0125-z.

— C. Li, and Y. Liu, 2004: Overview of the South China Sea monsoon experiment. Adv. Atmos. Sci., 21, 343-360, https:// doi.org/10.1007/BF02915563.

_ Y. Liu, Y. Song, and J. Zhang, 2015: From MONEX to the global monsoon: A review of monsoon system research. Adv. Atmos. Sci., 32, 10-31, https://doi.org/10.1007/s00376-014-0008-7.

Gill, A. E., 1980: Some simple solutions for heat-induced tropical circulation. Quart. J. Roy. Meteor. Soc., 106, 447-462, https:// doi.org/10.1002/qj.49710644905.

Guo, L., B. Q. Liu, and C. W. Zhu, 2019: Extraordinary long wet spell in south of Yangtze River during 2018/2019 winter and its possible causes. Chin. Sci. Bull., 64, 3498-3509.

He, B., Y. Zhang, T. Li, and W.-T. Hu, 2017: Interannual variability in the onset of the South China Sea summer monsoon from 1997 to 2014. Atmos. Oceanic Sci. Lett., 10, 73-81, https:// doi.org/10.1080/16742834.2017.1237853.

He, J., and Z. Zhu, 2015: The relation of South China Sea monsoon onset with the subsequent rainfall over the subtropical East Asia. Int. J. Climatol., 35, 4547-4556, https://doi.org/10.1002/ joc. 4305 .

Holton, J. R., and G. J. Hakim, 2013: An Introduction to Dynamic Meteorology. 5th ed. Academic Press, $532 \mathrm{pp.}$

Hu, P., W. Chen, R. Huang, and D. Nath, 2019: Climatological characteristics of the synoptic changes accompanying South China Sea summer monsoon withdrawal. Int. J. Climatol., 39, 596-612, https://doi.org/10.1002/joc.5828.

,-- , and,- 2018 a: Role of tropical intraseasonal oscillations in the South China Sea summer monsoon withdrawal in 2010. Atmos. Sci. Lett., 19, e859, https://doi.org/10.1002/asl.859.

,$--\ldots$, and D. Nath, 2018b: On the weakening relationship between the South China Sea summer monsoon onset and cross-equatorial flow after the late 1990s. Int. J. Climatol., 38, 3202-3208, https://doi.org/10.1002/joc.5472.

Huang, B., and Coauthors, 2017: Extended Reconstructed Sea Surface Temperature, version 5 (ERSSTv5): Upgrades, validations, and intercomparisons. J. Climate, 30, 8179-8205, https://doi.org/10.1175/JCLI-D-16-0836.1.

Huang, R., L. Gu, L. Zhou, and S. Wu, 2006: Impact of the thermal state of the tropical western Pacific on onset date and process of the South China Sea summer monsoon. Adv. Atmos. Sci., 23, 909-924, https://doi.org/10.1007/s00376-006-0909-1.

Huangfu, J., R. Huang, and W. Chen, 2017: Statistical analysis and a case study of tropical cyclones that trigger the onset of the South China Sea summer monsoon. Sci. Rep., 7, 12732, https://doi.org/10.1038/s41598-017-13128-2.

- W. When, X. Wang, and R. Huang, 2018: The role of synopticscale waves in the onset of the South China Sea summer monsoon. Atmos. Sci. Lett., 19, e858, https://doi.org/10.1002/asl.858.

Jiang, X., Z. Wang, and Z. Li, 2018: Signature of the South China Sea summer monsoon onset on spring-to-summer transition of rainfall in the middle and lower reaches of the Yangtze River basin. Climate Dyn., 51, 3785-3796, https://doi.org/10.1007/s00382-018-4110-x.

Johnson, N. C., M. L. L'Heureux, C.-H. Chang, and Z.-Z. Hu, 2019: On the delayed coupling between ocean and atmosphere in recent weak El Niño episodes. Geophys. Res. Lett., 46, 11 41611 425, https://doi.org/10.1029/2019GL084021.
Kajikawa, Y., and T. Yasunari, 2005: Interannual variability of the 10-25-and 30-60-day variation over the South China Sea during boreal summer. Geophys. Res. Lett., 32, L04710, https:// doi.org/10.1029/2004GL021836.

_ , and B. Wang, 2012: Interdecadal change of the South China Sea summer monsoon onset. J. Climate, 25, 3207-3218, https:// doi.org/10.1175/JCLI-D-11-00207.1.

Kanamitsu, M., W. Ebisuzaki, J. Woollen, S.-K. Yang, J. J. Hnilo, M. Fiorino, and G. L. Potter, 2002: NCEP-DOE AMIP-II Reanalysis (R-2). Bull. Amer. Meteor. Soc., 83, 1631-1644, https://doi.org/10.1175/BAMS-83-11-1631.

Krishnakumar, V., V. S. Kasture, and N. R. Keshavamurty, 1993 : Linear and non-linear studies of the summer monsoon onset vortex. J. Meteor. Soc. Japan, 71, 1-20, https://doi.org/10.2151/ jmsj1965.71.1_1.

Krishnamurti, T. N., P. Ardanuy, Y. Ramanathan, and R. Rasch, 1981: On the onset vortex of the summer monsoon. Mon. Wea. Rev., 109, 344-363, https://doi.org/10.1175/1520-0493(1981) $109<0344$ :OTOVOT $>2.0$. CO; 2

Kueh, M.-T., and S.-C. Lin, 2010: A climatological study on the role of the South China Sea monsoon onset in the development of the East Asian summer monsoon. Theor. Appl. Climatol., 99, 163-186, https://doi.org/10.1007/s00704-009-0136-7.

Lau, K., and S. Yang, 1997: Climatology and interannual variability of the Southeast Asian summer monsoon. Adv. Atmos. Sci., 14, 141-162, https://doi.org/10.1007/s00376-997-0016-y.

— , H.-T. Wu, and S. Yang, 1998: Hydrologic processes associated with the first transition of the Asian summer monsoon: A pilot satellite study. Bull. Amer. Meteor. Soc., 79, 1871-1882, https:// doi.org/10.1175/1520-0477(1998)079<1871:HPAWTF>2.0.CO;2.

_ , and Coauthors, 2000: A report of the field operations and early results of the South China Sea Monsoon Experiment (SCSMEX). Bull. Amer. Meteor. Soc., 81, 1261-1270, https://doi.org/10.1175/ 1520-0477(2000)081<1261:AROTFO > 2.3.CO;2.

Lee, J.-Y., B. Wang, M. C. Wheeler, X. Fu, D. E. Waliser, and I.-S. Kang, 2013: Real-time multivariate indices for the boreal summer intraseasonal oscillation over the Asian summer monsoon region. Climate Dyn., 40, 493-509, https://doi.org/ 10.1007/s00382-012-1544-4.

Li, C. Y., and W. Zhou, 2015: Multiscale control of summertime persistent heavy precipitation events over South China in association with synoptic, intraseasonal, and low-frequency background. Climate Dyn., 45, 1043-1057, https://doi.org/ 10.1007/s00382-014-2347-6.

Li, J., and L. Zhang, 2009: Wind onset and withdrawal of Asian summer monsoon and their simulated performance in AMIP models. Climate Dyn., 32, 935-968, https://doi.org/10.1007/ s00382-008-0465-8.

Li, T., 2014: Recent advance in understanding the dynamics of the Madden-Julian oscillation. J. Meteor. Res., 28, 1-33, https:// doi.org/10.1007/s13351-014-3087-6.

_- B. Wang, B. Wu, T. Zhou, C.-P. Chang, and R. Zhang, 2017: Theories on formation of an anomalous anticyclone in western North Pacific during El Niño: A review. J. Meteor. Res., 31, 987-1006, https://doi.org/10.1007/s13351-017-7147-6.

Li, X. Z., W. Zhou, and Y. Q. Chen, 2016: Detecting the origins of moisture over Southeast China: Seasonal variation and heavy rainfall. Adv. Atmos. Sci., 33, 319-329, https://doi.org/10.1007/ s00376-015-4197-5.

Li, Y., S. Yang, Y. Deng, and B. Zheng, 2020: Signals of spring thermal contrast related to the interannual variations in the onset of the South China Sea summer monsoon. J. Climate, 33, 27-38, https://doi.org/10.1175/JCLI-D-19-0174.1. 
Liang, J.-Y., Z.-P. Wen, J.-P. Chen, and L.-J. Wu, 2013: Characteristics of tropical sea surface temperature anomalies and their influences on the onset of South China Sea summer monsoon. Atmos. Oceanic Sci. Lett., 6, 266-272, https://doi.org/10.1080/16742834.2013.11447092.

Lin, A., D. Gu, C. Li, and B. Zheng, 2016: Impact of equatorial MJO activity on summer monsoon onset in the South China Sea. Chin. J. Geophys., 59, 28-44, https://doi.org/10.6038/ CJG20160104.

- R. Zhang, and C. He, 2017: The relation of cross-equatorial flow during winter and spring with South China Sea summer monsoon onset. Int. J. Climatol., 37, 4576-4585, https://doi.org/ 10.1002/joc.5106.

Liu, B., and C. Zhu, 2019: Extremely late onset of the 2018 South China Sea summer monsoon following a La Niña event: Effects of triple SST anomaly mode in the North Atlantic and a weaker Mongolian cyclone. Geophys. Res. Lett., 46, 2956-2963, https://doi.org/10.1029/2018GL081718.

_ , Y. Liu, G. Wu, J. Yan, J. He, and S. Ren, 2015: Asian summer monsoon onset barrier and its formation mechanism. Climate Dyn., 45, 711-726, https://doi.org/10.1007/s00382-014-2296-0.

_- C. Zhu, Y. Yuan, and K. Xu, 2016: Two types of interannual variability of South China Sea summer monsoon onset related to the SST anomalies before and after 1993/ 94. J. Climate, 29, 6957-6971, https://doi.org/10.1175/JCLID-16-0065.1.

Liu, X., Q. Li, J. He, and P. Wang, 2010: Effects of the thermal contrast between Indo-China Peninsula and South China Sea on the SCS monsoon onset. J. Meteor. Res., 24, 459-467.

Liu, Y., J. C. Chan, J. Mao, and G. Wu, 2002: The role of Bay of Bengal convection in the onset of the 1998 South China Sea summer monsoon. Mon. Wea. Rev., 130, 2731-2744, https://doi.org/10.1175/ 1520-0493(2002)130<2731:TROBOB >2.0.CO;2.

Luo, M., and L. Lin, 2017: Objective determination of the onset and withdrawal of the South China Sea summer monsoon. Atmos. Sci. Lett., 18, 276-282, https://doi.org/10.1002/asl.753.

—, Y. Leung, H. F. Graf, M. Herzog, and W. Zhang, 2016: Interannual variability of the onset of the South China Sea summer monsoon. Int. J. Climatol., 36, 550-562, https:// doi.org/10.1002/joc. 4364 .

Mao, J., and G. Wu, 2008: Influences of Typhoon Chanchu on the 2006 South China Sea summer monsoon onset. Geophys. Res. Lett., 35, L12809, https://doi.org/10.1029/2008GL033810.

Martin, G. M., A. Chevuturi, R. E. Comer, N. J. Dunstone, A. A. Scaife, and D. Zhang, 2019: Predictability of South China Sea summer monsoon onset. Adv. Atmos. Sci., 36, 253-260, https:// doi.org/10.1007/s00376-018-8100-z.

Matsuno, T., 1966: Quasi-geostrophic motions in the equatorial area. J. Meteor. Soc. Japan, 44, 25-43, https://doi.org/10.2151/ jmsj1965.44.1_25.

Murakami, M., 1979: Large-scale aspects of deep convective activity over the GATE area. Mon. Wea. Rev., 107, 994-1013, https:// doi.org/10.1175/1520-0493(1979)107<0994:LSAODC>2.0.CO;2.

Qiao, Y., C. Zhang, and M. Jian, 2015: Role of the 10-20-day oscillation in sustained rainstorms over Hainan, China in October 2010. Adv. Atmos. Sci., 32, 363-374, https://doi.org/ 10.1007/s00376-014-3200-x.

Rong, X. Y., R. H. Zhang, and T. Li, 2010: Impacts of Atlantic sea surface temperature anomalies on Indo-East Asian summer monsoon-ENSO relationship. Chin. Sci. Bull., 55, 2458-2468, https://doi.org/10.1007/s11434-010-3098-3.

Schreck, C., H.-T. Lee, and K. Knapp, 2018: HIRS outgoing longwave radiation-Daily climate data record: Application toward identifying tropical subseasonal variability. Remote Sens., 10, 1325, https://doi.org/10.3390/rs10091325.

Shao, X., P. Huang, and R.-H. Huang, 2015: Role of the phase transition of intraseasonal oscillation on the South China Sea summer monsoon onset. Climate Dyn., 45, 125-137, https:// doi.org/10.1007/s00382-014-2264-8.

Straub, K. H., G. N. Kiladis, and P. E. Ciesielski, 2006: The role of equatorial waves in the onset of the South China Sea summer monsoon and the demise of El Niño during 1998. Dyn. Atmos. Oceans, 42, 216-238, https://doi.org/10.1016/ j.dynatmoce.2006.02.005.

Tong, H., J. C. Chan, and W. Zhou, 2009: The role of MJO and midlatitude fronts in the South China Sea summer monsoon onset. Climate Dyn., 33, 827-841, https://doi.org/10.1007/s00382-0080490-7.

Torrence, C., and G. P. Compo, 1998: A practical guide to wavelet analysis. Bull. Amer. Meteor. Soc., 79, 61-78, https://doi.org/ 10.1175/1520-0477(1998)079<0061:APGTWA > 2.0.CO;2.

Wang, B., and R. Wu, 1997: Peculiar temporal structure of the South China Sea summer monsoon. Adv. Atmos. Sci., 14, 177194, https://doi.org/10.1007/s00376-997-0018-9.

, and LinHo, 2002: Rainy season of the Asian-Pacific summer monsoon. J. Climate, 15, 386-398, https://doi.org/10.1175/ 1520-0442(2002)015<0386:RSOTAP $>2.0$. CO;2.

, and Y. Kajikawa, 2015: Reply to "Comments on 'interdecadal change of the South China Sea summer monsoon onset." J. Climate, 28, 9036-9039, https://doi.org/10.1175/ JCLI-D-15-0173.1.

$\longrightarrow$, R. Wu, and X. Fu, 2000: Pacific-East Asian teleconnection: How does ENSO affect East Asian climate? J. Climate, 13, 1517-1536, https://doi.org/10.1175/1520-0442(2000)013<1517: PEATHD $>2.0 . \mathrm{CO} ; 2$.

, LinHo, Y. Zhang, and M. Lu, 2004: Definition of South China Sea monsoon onset and commencement of the East Asia summer monsoon. J. Climate, 17, 699-710, https://doi.org/ 10.1175/2932.1.

_ , F. Huang, Z. Wu, J. Yang, X. Fu, and K. Kikuchi, 2009: Multiscale climate variability of the South China Sea monsoon: A review. Dyn. Atmos. Oceans, 47, 15-37, https://doi.org/10.1016/ j.dynatmoce.2008.09.004.

Wang, H., F. Liu, B. Wang, and T. Li, 2018: Effects of intraseasonal oscillation on South China Sea summer monsoon onset. Climate Dyn., 51, 2543-2558, https://doi.org/10.1007/s00382017-4027-9.

Wang, L., and G. Chen, 2018: Relationship between South China Sea summer monsoon onset and landfalling tropical cyclone frequency in China. Int. J. Climatol., 38, 3209-3214, https:// doi.org/10.1002/joc.5485.

Wang, X., D. X. Wang, W. Zhou, and C. Y. Li, 2012: Interdecadal modulation of the influence of La Niña events on mei-yu rainfall over the Yangtze River Valley. Adv. Atmos. Sci., 29, 157-168, https://doi.org/10.1007/s00376-011-1021-8.

Webster, P. J., and S. Yang, 1992: Monsoon and ENSO: Selectively interactive systems. Quart. J. Roy. Meteor. Soc., 118, 877-926, https://doi.org/10.1002/qj.49711850705.

Wheeler, M. C., and H. H. Hendon, 2004: An all-season real-time multivariate MJO index: Development of an index for monitoring and prediction. Mon. Wea. Rev., 132, 1917-1932, https://doi.org/ 10.1175/1520-0493(2004)132<1917:AARMMI > 2.0.CO;2.

Wu, C., S. Yang, A. Wang, and S. Fong, 2005: Effect of condensational heating over the Bay of Bengal on the onset of the South China Sea monsoon in 1998. Meteor. Atmos. Phys., 90, 37-47, https://doi.org/10.1007/s00703-005-0115-1. 
Wu, G., and Y. Zhang, 1998: Tibetan Plateau forcing and the timing of the monsoon onset over South Asia and the South China Sea. Mon. Wea. Rev., 126, 913-927, https://doi.org/10.1175/ 1520-0493(1998)126<0913:TPFATT >2.0.CO;2.

—, Y. Guan, Y. Liu, J. H. Yan, and J. Y. Mao, 2012: Air-sea interaction and formation of the Asian summer monsoon onset vortex over the Bay of Bengal. Climate Dyn., 38, 261279, https://doi.org/10.1007/s00382-010-0978-9.

Wu, R., 2002: Processes for the northeastward advance of the summer monsoon over the western North Pacific. J. Meteor. Soc. Japan, 80, 67-83, https://doi.org/10.2151/jmsj.80.67.

_ 2010 : Subseasonal variability during the South China Sea summer monsoon onset. Climate Dyn., 34, 629-642, https:// doi.org/10.1007/s00382-009-0679-4.

— , and B. Wang, 2001: Multi-stage onset of the summer monsoon over the western North Pacific. Climate Dyn., 17, 277 289, https://doi.org/10.1007/s003820000118.

Xie, A., Y.-S. Chung, X. Liu, and Q. Ye, 1998: The interannual variations of the summer monsoon onset over the South China Sea. Theor. Appl. Climatol., 59, 201-213, https://doi.org/ 10.1007/s007040050024.

Xie, S.-P., and S. G. H. Philander, 1994: A coupled ocean-atmosphere model of relevance to the ITCZ in the eastern Pacific. Tellus, 46A, 340-350, https://doi.org/10.3402/tellusa.v46i4.15484.

- K. Hu, J. Hafner, H. Tokinaga, Y. Du, G. Huang, and T. Sampe, 2009: Indian Ocean capacitor effect on Indo-western Pacific climate during the summer following El Niño. J. Climate, 22, 730-747, https://doi.org/10.1175/2008JCLI2544.1.

, Y. Kosaka, Y. Du, K. Hu, J. S. Chowdary, and G. Huang, 2016: Indo-western Pacific Ocean capacitor and coherent climate anomalies in post-ENSO summer: A review. Adv. Atmos. Sci., 33, 411-432, https://doi.org/10.1007/s00376-015-5192-6.
Xing, N., J. Li, and L. Wang, 2016: Effect of the early and late onset of summer monsoon over the Bay of Bengal on Asian precipitation in May. Climate Dyn., 47, 1961-1970, https://doi.org/ 10.1007/s00382-015-2944-z.

Yu, W.-D., K.-P. Li, J.-W. Shi, L. Liu, H.-W. Wang, and Y.-L. Liu, 2012: The onset of the monsoon over the Bay of Bengal: The year-to-year variations. Atmos. Oceanic Sci. Lett., 5, 342-347, https://doi.org/10.1080/16742834.2012.11447011.

Yuan, Y., W. Zhou, J. C. Chan, and C. Li, 2008: Impacts of the basin-wide Indian Ocean SSTA on the South China Sea summer monsoon onset. Int. J. Climatol., 28, 1579-1587, https://doi.org/10.1002/joc.1671.

Zhang, R., A. Sumi, and M. Kimoto, 1996: Impact of El Niño on the East Asian Monsoon: A diagnostic study of the ' $86 / 87$ and '91/92 events. J. Meteor. Soc. Japan, 74, 49-62, https://doi.org/ 10.2151/jmsj1965.74.1_49.

— Q. Min, and J. Su, 2017: Impact of El Niño on atmospheric circulations over East Asia and rainfall in China: Role of the anomalous western North Pacific anticyclone. Sci. China Earth Sci., 60, 1124-1132, https://doi.org/10.1007/s11430-016-9026-x.

Zhou, W., and J. C. L. Chan, 2005: Intraseasonal oscillations and the South China Sea summer monsoon onset. Int. J. Climatol., 25, 1585-1609, https://doi.org/10.1002/joc.1209.

— , and - 2007: ENSO and the South China Sea summer monsoon onset. Int. J. Climatol., 27, 157-167, https://doi.org/ $10.1002 /$ joc. 1380 .

,-- , and C. Li, 2005: South China Sea summer monsoon onset in relation to the off-equatorial ITCZ. Adv. Atmos. Sci., 22, 665-676, https://doi.org/10.1007/BF02918710.

Zhu, Z., and T. Li, 2017: Empirical prediction of the onset dates of South China Sea summer monsoon. Climate Dyn., 48, 1633 1645, https://doi.org/10.1007/s00382-016-3164-x. 